\title{
LA VOZ DEL NARRADOR EN LAS NOVELAS DE JAVIER MARÍAS
}

SANDRA NAVARRO GIL Universidad de La Rioja

La primera novela de Javier Marías, Los dominios del lobo, apareció hace más de treinta años, exactamente en 1971. Desde entonces el autor no ha dejado de publicar, si bien nunca se ha visto dominado por las exigencias y presiones del actual mercado editorial. Nueve novelas, dos colecciones de relatos y una abundante y continuada labor como articulista y ensayista, recogida hasta hoy en siete volúmenes, completan la producción de Javier Marías. Aunque nadie pone en duda la importancia de este autor en la narrativa de las últimas letras, lo cierto es que su obra sigue siendo hoy mismo casi una desconocida para la crítica literaria española ${ }^{1}$. La narrativa de Javier Marías, muy apreciada fuera de nuestras fronteras, es una de las asignaturas pendientes de los estudios literarios españoles. De hecho, breves menciones en los manuales de literatura contemporánea y apresuradas reseñas periodísticas o informativas constituyen el grueso del material crítico disponible en España sobre las creaciones de este escritor ${ }^{2}$.

Creo que una revisión rigurosa de la producción literaria de este autor debe partir del análisis de la figura del narrador en el conjunto de su narrativa. La voz del narrador, eje sobre el que gira la estructura del discurso narrativo, va a definir la obra de Javier Marías especialmente tras la publicación de El hombre sentimental en 1986, novela clave en la trayectoria

\footnotetext{
' Eduardo Mendoza reflexiona sobre el «fenómeno Marías» en un interesante artículo publicado en El País. Mendoza llega a la conclusión de que «la obra de Javier Marías crea un desconcierto incómodo. Nadie sabe muy bien cómo clasificarla ni calificarla». Véase Eduardo MENDOZA, «El extraño caso de Javier Marías», El País, 18/11/1998, p. 40.

${ }^{2}$ Únicamente la editorial Rodopi se ha encargado de revisar con rigor la obra completa de Javier Marías. En octubre del 2001 apareció el monográfico El pensamiento literario de Javier Marías (Amsterdam, Rodopi, 2001), coordinado por Maarten Steenmeijer, y un año después veía la luz Coming Into One's Own, The Novelistic Development of Javier Marías de Alexis Grohmann, Editions Rodopi (Portada Hispánica 13), Amsterdam/New York, NY., 2002.
}

Rlit, LXV, 129 (2003), 199-210 
literaria del autor. El propio escritor, que, por cierto, siempre se ha mostrado más inclinado hacia la autocrítica que a respetar la tarea de los críticos literarios, hace hincapié en este aspecto al hablar de su narrativa en una entrevista: «En mis novelas es muy importante quién tiene la voz [...] Tengo clara conciencia de que quien puede tener voz, puede mostrarse» ${ }^{3}$.

La importancia del narrador en el texto literario ha sido destacada en numerosos estudios de teoría literaria. En primer lugar, hay que tener en cuenta que a través del filtro del narrador llega toda la información contenida en la narración. La voz narradora es la única responsable del relato. En este punto tal vez convenga recordar la excelente definición de narrador que M. ${ }^{a}$ del Carmen Bobes Naves ofrece en su estudio La novela: «el narrador, esa persona ficta, situada entre el mundo empírico del autor y de los lectores y el mundo ficcional de la novela, y que a veces pasa al mundo de la ficción como un personaje observador, es el centro hacia el que convergen todos los sentidos que podemos encontrar en una novela, y del que parten todas las manipulaciones que se pueden señalar en ella, pues es quien dispone de la voz del discurso y de los conocimientos del mundo narrado, él es quien da cuenta de los hechos, el que elige el orden, el que usa las palabras en la forma que cree más conveniente, y a partir de aquí reconstruye con un discurso verbal un relato novelesco, dotado de sentido propio que procede del conjunto de las unidades textuales y de sus relaciones» ${ }^{4}$. En palabras de Antonio Garrido Domínguez: «El narrador constituye sin duda alguna el elemento central del relato. Todos los demás componentes experimentan de un modo $\mathrm{u}$ otro los efectos de la manipulación a que es sometido por él el material de la historia» ${ }^{5}$.

La evolución de la voz del narrador en las obras de Javier Marías, tanto en sus novelas como en sus relatos, que siguen una curiosa y paralela trayectoria, es la clave necesaria para entender una narrativa que nunca se movió a gusto en los moldes narrativos clásicos y que, por la misma razón, ha experimentado deśde sus inicios sobre los diversos modos de entender la literatura. De hecho, la reflexión sobre el lenguaje y sobre el propio acto de la narración son dos constantes en la obra de Javier Marías: «contar es una forma de generosidad» afirma el narrador protagonista de Mañana en la batalla piensa en mí (1994), quien también llegará a la tajante conclusión de que «el mundo depende de sus relatores».

Las dos primeras novelas de aventuras de Javier Marías, Los dominios del lobo (1971) y Travesía del horizonte (1972) precisaban de un narrador distante e irónico que llevara a cabo el afán lúdico o de evasión que per-

\footnotetext{
${ }^{3}$ Luis H. CASTELlanos, «La magia de lo que pudo ser. Entrevista con Javier Marías», Quimera, n. ${ }^{\circ} 87,1989$, p. 29.

${ }^{4}$ M. ${ }^{a}$ del Carmen Bobes NAVES, La novela. Madrid, Síntesis, 1993, p. 197.

5 Antonio Garrido Domínguez, El texto narrativo. Madrid, Síntesis, 1993, p. 105.
} 
siguen ambos relatos: estamos ante dos ejemplos rotundos de literatura entendida como juego.

Los dominios del lobo, el estreno literario de Javier Marías, representó una novedad en el todavía acartonado panorama narrativo de los primeros setenta. Realmente este pastiche de las películas del cine americano que el entonces aspirante a escritor veía por docenas ponía de manifiesto la necesidad de cambios en la literatura española del momento. La cultura cinematográfica se adentraba en la narrativa española sin reservas ni escrúpulos. En Los dominios del lobo se destaca el referente cinematográfico en un consciente y premeditado alejamiento de los supuestos de la realidad. El texto literario es un mundo autónomo que comienza y termina en las páginas del libro y que, además, no necesita tomar como modelo el mundo de las cosas reales. Los personajes planos y desdibujados, la trepidante acción de los varios y disparatados relatos que integran la narración, el desorden temporal y la descomposición del espacio son algunos de los factores en los que se basa este proyecto de adolescencia -Marías tenía 19 años cuando acabó este trabajo-. El narrador apropiado para esta novela lúdica es lo más parecido a un narrador omnisciente en versión cinematográfica: el distante y algo irónico narrador de Los dominios del lobo bien podría ser un director de cine que se dedicara a filmar con una cámara diferentes secuencias de películas con el único objeto de divertir y divertirse.

La segunda novela de Marías, Travesía del horizonte, publicada sólo un año después, en 1972, también puede ser encasillada dentro del género de las novelas de aventuras. Esta vez el referente directo es la novela inglesa del XIX - piénsese en las creaciones de Joseph Conrad, Henry James y Conan Doyle - y la narración, de nuevo, se limita a imitar el estilo de las novelas a las que se homenajea y parodia al mismo tiempo. Si dejamos a un lado su siguiente novela El monarca del tiempo (1978), una miscelánea con afán experimental que consta de cinco partes escritas en géneros distintos (relato, ensayo y drama), es ya en El siglo (1983) en donde empieza a cobrar importancia la figura del narrador en la producción de Javier Marías. Precisamente la peculiaridad de esta novela consiste en el empleo de dos voces narrativas: una voz narrativa en primera persona cuenta su historia desde un presente en el que es un anciano en los capítulos impares de la novela mientras que los capítulos pares corren a cargo de una voz omnisciente que relata los hechos decisivos del pasado del protagonista. Ambas perspectivas intentan ofrecer una «visión total», desde dentro y desde fuera, en el pasado y en el presente, que ayude a forjar la reconstrucción del controvertido personaje protagonista Casaldáliga.

Será en la siguiente novela de Marías, El hombre sentimental, en la que aparezca la voz narrativa que va a ser la elegida para el resto de sus ficciones. El narrador de El hombre sentimental es un cantante de ópera que nos relata una desafortunada experiencia amorosa a la vez que se deja 
llevar por otras reflexiones que le asaltan al transcribir sus recuerdos. Este personaje, que ya había aparecido de pasada en El monarca del tiempo -concretamente, en el segundo fragmento titulado «Portento, maldición» cuyo narrador es el señor Casaldáliga, su padrino y protector- y que es personaje secundario de El siglo, termina por hacerse cargo de la narración y, de algún modo, logra contar su verdad. Al tomar prestada la voz el León tiene la última palabra y puede resarcirse del cruel testimonio de Casaldáliga. La memoria, junto a la imaginación y el sueño que añaden los datos que se escapan de continuo en la experiencia de la realidad, son los ingredientes de una narración que se pierde en los vericuetos del interior del narrador. El resultado es un relato en espiral que se entretiene en las divagaciones y consideraciones al margen del hilo argumental con las que el narrador enriquece su historia.

El empleo de la voluntariosa voz narradora en primèra persona se afianza en Todas las almas (1989). El relato del narrador de Todas las almas comienza con la rememoración de su estancia como profesor visitante en Oxford durante dos cursos. Esa época de su vida, que el protagonista narrador siente como «una perturbación», precisa ser relatada para ser olvidada después. El presente diáfano y terso localizado en el Madrid natal contrasta con el rugoso pasado que el narrador vivió en Oxford. De aquí que sea necesario un esfuerzo de memoria y de escritura que logre poner en orden esa etapa de perturbación. También Javier Marías había sido profesor en Oxford durante dos cursos y algunas de las anécdotas que le ocurren al Español en la novela habían sido contadas por el autor como propias en artículos de periódicos ${ }^{6}$. La identificación autor/narrador era inevitable. El propio escritor ha reconocido el cambio entre ésta y sus anteriores novelas y los nuevos matices de una narración que partía en gran parte de su experiencia personal -el viaje a Oxford, anécdotas de su infancia madrileña, la investigación sobre el malogrado escritor John Gawsworth-y del deliberado encubrimiento de la identidad del narrador protagonista, denominado en el relato «el Español» o «el caballero español»: «Aquí no rehuí mi propia voz, esto es, mi dicción habitual o natural por escrito, la de - por ejemplo- las cartas que había escrito a mis amigos cuando estaba en Inglaterra. Sin embargo, pese a que a ese personaje, el Narrador o Español, yo le estuviera prestando mi propia voz y parte de mis experiencias, yo sabía que no se trataba de mí, sino de alguien distinto de mí, aunque parecido. Si se prefiere, se puede utilizar la fórmula de que ese personaje era 'quien yo pude ser pero no fui' ${ }^{7}$.

${ }^{6}$ En el artículo «Por fin nos envidian» (1985), Javier Marías comenta algunas anécdotas de su estancia en Oxford que van a ser «ficcionalizadas» en Todas las almas. El artículo está recogido en Vida del fantasma. Madrid, El País-Aguilar, 1995, pp. 313-315.

7 Javier MARÍAS, «Quién escribe» (1989), recopilado en Literatura y fantasma. Madrid, Siruela, 1993, pp.83-90. El subrayado es mío. El autor ha manifestado en varias ocasiones que la ficción es el reino de lo que pudo ser. 
Marías se refugia así intencionadamente en el terreno ambiguo en el que se mezclan realidad y ficción: se trata de ficcionalizar la realidad con el fin de ofrecer un relato a medio camino entre las memorias y la invención. Al aprovechar ciertos aspectos de la experiencia personal y presentarlos como ficción se crea un nuevo subgénero literario que no es propiamente ni un relato inventado - una ficción en el sentido estricto del término- ni una autobiografía o memorias al uso. A propósito de este asunto, el escritor reflexionaba en su artículo «Autobiografía y ficción» de 1987 sobre el que va a ser su nuevo reto literario, abordar el campo autobiográfico como ficción: «el autor presenta su obra como obra de ficción, o al menos no indica que no lo sea; es decir, en ningún momento se dice o se advierte que se trate de un texto autobiográfico o basado en hechos 'verídicos' o 'verdaderos' o 'no inventados'. Sin embargo, la obra en cuestión tiene todo el aspecto de una confesión, y además el narrador recuerda claramente al autor, sobre el cual solemos tener alguna información, sea en el propio libro, sea fuera de él» ${ }^{8}$.

Esta delicada fórmula que consiste en la narración de la propia experiencia desde una estructura ficticia ha sido denominada por la crítica «autoficción» ${ }^{9}$. Manuel Alberca afirma que son relatos autofictivos aquellos «que se caracterizan por presentarse como novelas, es decir, como ficción, y al mismo tiempo tienen una apariencia autobiográfica ratificada por la identidad del autor, narrador y personaje». Alberca señala Todas las almas como el ejemplo mejor acabado de autoficción en la literatura española, al que siguen El dueño del secreto de Antonio Muñoz Molina e Historia de un idiota contada por él mismo de Félix de Azúa ${ }^{10}$.

Al comienzo de su relato el narrador de Todas las almas hace una importante consideración sobre su acto narrativo. El narrador advierte de que aunque cuenta su propia experiencia no es el mismo personaje que la sufrió. El que «entonces era» no es el mismo que ahora narra esa historia que pertenece a su pasado. El narrador alude de este modo a la distinción entre los dos conocidos conceptos del teórico Gérard Genette, foco y voz. El foco de la historia es ese «yo» del narrador que pasó dos años en la muy culta ciudad de Oxford, que sin embargo no es el mismo «yo» que narra en el presente, la voz que cuenta: el narrador del presente va a aportar a su relato los pensamientos y las emociones que tras el tiempo esa

\footnotetext{
${ }^{8}$ Javier MARÍAS, «Autobiografía y ficción» (1987), recogido en Literatura y fantasma, op. cit., pp. 62-69.

9 El concepto de «autoficción» está desarrollado ampliamente en el estudio de Alicia Molero De LA Iglesia, La autoficción en España. Jorge Semprún, Carlos Barral, Luis Goytisolo, Enriqueta Antolín y Antonio Muñoz Molina. Bern, Peter Lang, 2000.

${ }^{10}$ Véase VVAA, «Prosa autobiográfica y literatura», Historia y crítica de la literatura española. 9/1. Los nuevos nombres: 1975-2000, Jordi Gracia ed., edición al cuidado de Francisco Rico. Barcelona, Crítica, 2000, p. 425.
} 
experiencia ha dejado en su ánimo. De hecho, la actividad de contar de algún modo tergiversa los hechos: «Pero para hablar de ellos tengo que hablar también de mí, y de mi estancia en la ciudad de Oxford. Aunque el que habla no sea el mismo que estuvo allí. Lo parece, pero no es el mismo. [...] El que aquí cuenta lo que vio y le ocurrió no es aquel que lo vio y al que le ocurrió, ni tampoco es su prolongación, ni su sombra, ni su heredero, ni su usurpador» ${ }^{11}$.

En Todas las almas se parte de la pasada estancia oxoniense del narrador, pero pronto nos instalaremos en el presente de la historia: «En el breve espacio de tiempo transcurrido desde que abandoné la ciudad de Oxford demasiadas cosas han cambiado o han empezado o han dejado de ser. Ahora ya no vivo solo en el extranjero, sino que me he casado y vivo en Madrid otra vez. Tengo un hijo» ${ }^{12}$.

Las cosas no sólo han cambiado para el narrador. El tiempo todo lo transforma, y, de hecho, dos de los personajes principales del relato ya han muerto en el momento de la rememoración, Cromer-Blake y Toby Rylands. La voz de estos personajes acompañará, junto a la de la amante de El Español, Clare Bayes, el pausado discurso del narrador de Todas las almas, que a veces parece exhausto en su esfuerzo por hacer memoria y escribir lo recordado. Estos seres que poblaban la estática ciudad de Oxford, y sus misterios, quedan a la postre inmersos en el pasado. El presente pertenece, en cambio, al narrador que sigue vivo y «fantaseando con lo que ha de venir».

Como en la novela que le precede, la siguiente novela de Javier Marías Corazón tan blanco (1992) tiene la forma de un libro de memorias, las del narrador, que parten del conocimiento de un hecho que perteneció al pasado y que logra instalarse en el presente. Hasta que tiene lugar la revelación de ese secreto que nunca debió salir a la luz, una serie de premoniciones y una desasosegante sensación de desastre se apoderan del tranquilo acontecer de la vida del narrador. Los síntomas llegan poco después de su matrimonio con Luisa, concretamente durante el viaje de novios en La Habana. Poco a poco se nos desvelará el secreto que, como el personaje, casi preferíamos ignorar: su padre mató a su primera esposa para casarse con Teresa Aguilera, la mujer cuyo suicidio se nos narra al comienzo de la novela. La vida, la muerte, la palabra y el silencio, saber o ignorar, lo pasado y el futuro son las parejas de contrarios que se entremezclan en la narración y en la vida misma: el paso de un opuesto a otro depende más de las palabras que de los hechos, pues las palabras siempre conde-

\footnotetext{
11 Javier MARíAs, Todas las almas. Barcelona, Círculo de Lectores, 1996, 1989¹, p. 19.

12 Javier MARías, op. cit., p. 105. Ninguno de estos dos hechos han sucedido hasta ahora en la vida del autor. Javier Marías se apoya en estos datos biográficos para evitar la identificación narrador/autor que le ha perseguido desde la publicación de la novela.
} 
nan (especialmente al que las escucha) y los hechos pueden esconderse $\mathbf{u}$ olvidarse, como hizo Ranz, el padre del narrador, con el asesinato de su mujer cubana cuarenta años atrás.

Las historias y los personajes que acompañan al relato principal y, sobre todo, las continuas y densas digresiones del narrador cumplen una función esencial en el discurso narrativo. Ante el conocimiento de lo que ya no es secreto para él, el narrador siente la necesidad, a su vez, de contar para asimilar los hechos. Las alusiones a su actividad narradora son constantes durante su discurso. De hecho, no duda en prevenirnos de «esas voces narrativas que todos tenemos y que se remontan hasta el pasado remoto o reciente y descubren secretos que ya no importan y sin embargo influyen en la vida o los venideros años, en nuestro conocimiento del mundo y de las personas, no se puede confiar en nadie después de escucharlas, es todo posible, el mayor horror y la mayor vileza en las personas que conocemos, como en nosotros mismos» ${ }^{13}$.

Desenterrado definitivamente el pasado, el narrador vuelve a concentrarse en el presente y en el futuro abstracto, al que parece encararse ahora libre de ataduras y con la sensación de que «nada de lo que sucede sucede, de que todo ocurrió y a la vez no ocurrió» ${ }^{14}$.

Dos años después aparece Mañana en la batalla piensa en mí, novela por la que Javier Marías ha sido galardonado con prestigiosos premios internacionales como el Premio Fastenrath 1995, el Premio Internacional Rómulo Gallegos 1995 o el Prix Femina Étranger 1996, entre otros. Otra vez una voz narradora en primera persona nos hará partícipes de un hecho turbador de su pasado. En este caso es la muerte de la que está a punto de convertirse en amante el suceso que pone en marcha la atribulada mente del narrador: qué hacer tras presenciar esa muerte, avisar al marido de la mujer que se encuentra de viaje de negocios en Londres o abandonar la casa y dejar solo al niño pequeño que duerme tranquilamente en su cuarto. Esta vez es el encubrimiento de la muerte de la mujer por parte del narrador Víctor Francés el que va a provocar el desastre. Si en la novela anterior se defendía el mantenimiento de los secretos en este trabajo de Marías se resalta el perjuicio del silencio. La ocultación de este hecho fatal va a provocar consecuencias irreparables que terminarán afectando a los demás personajes de la novela. En su relato Víctor Francés seguirá el curso de unos pensamientos centrados en densas reflexiones acerca del tiempo, la vida y la muerte, a la vez que va desvelando mediante incisos los hechos que se produjeron a raíz de la muerte de Marta.

Estas tres novelas de Javier Marías, Todas las almas, Corazón tan blanco y Mañana en la batalla piensa en mí, publicadas entre 1989 y 1994,

\footnotetext{
${ }^{13}$ Javier MARÍAS, Corazón tan blanco. Barcelona, Anagrama, 1996, 1992 , p. 222.

14 Javier MARÍAS, Corazón tan blanco, op. cit., p. 294.
} 
presentan, como se ha visto, una misma disposición del relato. Las tres narraciones comienzan descubriendo el desenlace de la historia que se va a narrar. A modo de sumario, en los primeros párrafos se condensa el final de las historias que después los narradores procederán a explicar o a analizar, aunque nunca de una forma lineal. Otras historias surgirán en la mente de estos relatores que no cesan de encontrar similitudes entre unos acontecimientos y otros. De hecho, los paralelismos, las asociaciones, los vínculos más insospechados serán muy frecuentes en el enmarañado discurso de los narradores de las novelas de madurez de Javier Marías. La dosificación de la información es, por su parte, otro de los grandes logros de estas creaciones. El relato de estos narradores se caracteriza por presentar un interesante juego de luces y de sombras: el discurso sólo avanza gracias a los incisos reflexivos del narrador. De hecho, lo más importante en las novelas de Javier Marías no es nunca lo que se cuenta - la historia o las anécdotas del relato- sino cómo se cuenta. En la narrativa del autor siempre importa más el cómo que el qué. La trama de las novelas es sólo la excusa que pone en marcha el acto de la narración: la propia actividad del contar es, así, el objetivo último del relato.

Los narradores de estas tres novelas de Javier Marías muestran un conocimiento sesgado respecto de los hechos que relatan. Según Javier Marías, «cualquier narrador en primera persona, si es verosímil, es un narrador fragmentario, con sus dudas y disyuntivas» ${ }^{15}$. La incertidumbre que muestran los narradores de Marías sobre el conocimiento de la realidad se entiende muy bien dentro del contexto histórico-filosófico en el que tienen lugar estas narraciones. Como es sabido, el individualismo y el relativismo propios del pensamiento de finales del siglo $\mathrm{XX}$ tienen su reflejo en una literatura en la que se pone de relieve la incredulidad ante una verdad única o absoluta. El narrador de El hombre sentimental, el protagonista de El siglo y los personajes de las novelas de aventuras de la primera época creativa de Javier Marías también tienen en común con los narradores de estas novelas la pasividad y la indecisión con la que se enfrentan a la realidad: su escasísima capacidad de acción se complementa con una acusada tendencia a divagar o a meditar sobre lo que les rodea ${ }^{16}$.

Con todo, y a pesar de sus limitaciones, la voz del narrador es la única realidad del relato, como expresa Óscar Tacca ${ }^{17}$. El narrador de Mañana en la batalla piensa en mí proclama del siguiente modo la soberanía de

\footnotetext{
${ }^{15}$ Arantza FurundarenA, «Entrevista a Javier Marías», El Semanal, 2/1/2000, p. 40.

${ }^{16}$ El propio Javier Marías ha afirmado en más de una ocasión que la indecisión es uno de los rasgos de su carácter: «Yo creo que lo que soy, la palabra más adecuada, es que soy un indeciso». Véase Rosa MONTERO, «Javier Marías: En estado de gracia». Entrevista, El País Semanal, 23/8/1992, p. 29.

17 Óscar TACCA, Las voces de la novela. Madrid, Gredos, 1985, p. 69. Son muy apreciables las reflexiones sobre el narrador que aporta el capítulo tercero de este trabajo.
} 
su voz: «Nadie me creería si lo dijera, lo cual sin embargo no importa mucho, ya que soy yo quien está contando, y se me escucha o no se me escucha, eso es todo» ${ }^{18}$. De aquí también se desprende la omnipresencia de la voz que cuenta. Buena parte de los personajes de la narrativa de Javier Marías se expresan igual que sus narradores —en este sentido son reveladores los soliloquios que protagonizan en Todas las almas Toby Rylands y Clare Bayes-. No hay que olvidar que el narrador relata de memoria los encuentros o escenas que después ofrece «en directo» a sus destinatarios: las voces que aparecen en las novelas de Marías son tan sólo creaciones del omnipotente narrador, que domina por completo el relato.

La identificación autor/narrador que tuvo lugar tras la publicación de Todas las almas sigue siendo posible en Corazón tan blanco y en Mañana en la batalla piensa en mí. Sin embargo, es en su hasta ahora último trabajo largo Negra espalda del tiempo (1998) en donde Marías se presenta a sí mismo como autor, narrador y protagonista de su relato: no hay voces postizas ni prestadas, el escritor Javier Marías opta en esta ocasión por convertirse en el personaje protagonista de esta «especie» de novela que se burla de los límites establecidos entre realidad y ficción. Del siguiente modo presenta el autor su experimento narrativo: «voy a relatar lo ocurrido o averiguado o tan sólo sabido - lo ocurrido en mi experiencia, o en mi fabulación, o en mi conocimiento, o es todo sólo conciencia que nunca cesa- a raíz de la escritura y divulgación de una novela, de una obra de ficción [...] para mí tiene la diversión del riesgo de contar sin motivo ni apenas orden y sin trazar dibujo ni buscar coherencia, como si lo hiciera con una voz antojadiza e imprevisible pero que conocemos todos, la voz del tiempo cuando aún no ha pasado ni se ha perdido y quizá por eso ni siquiera es tiempo, quizá lo sea sólo el que ha transcurrido y puede contarse o así parece, y que por eso es el único ambiguo. Creo que esa voz que oímos es siempre ficticia, tal vez lo será aquí la mía» ${ }^{19}$.

De este modo la voz de Javier Marías se asimila a la voz del tiempo cuando se sitúa en el ámbito de su negra espalda, como si se tratara de un fantasma que ve el mundo con la inmunidad que otorga el saberse fuera de él. De hecho, la figura del fantasma, una de sus preferidas, aparece frecuentemente en sus textos, tanto en los de ficción como en sus artículos y ensayos: «Todo escritor, yo creo, se asemeja un poco a esta figura: habla e influye, pero no siempre se deja ver; a veces desaparece o calla durante largo rato, en otras ocasiones arma grandes estrépitos con sus ficticias cadenas o intenta ahuyentar con su sábana blanca de intangibles

18 Javier MARíAS, Mañana en la batalla piensa en mí. Madrid, Alfaguara, 1997, 1994', p. 13.

19 Javier MARíAS, Negra espalda del tiempo. Madrid, Alfaguara, 1998, p. 11. 
palabras. No está del todo presente, pero asiste a los acontecimientos, y sobre todo ronda» ${ }^{20}$.

En Negra espalda del tiempo el autor se propone novelar sus propias experiencias tras la publicación de Todas las almas, ficción que parece empeñada en abandonar su naturaleza de papel y pasar a formar parte de la realidad de Javier Marías. Sin embargo, no hay que olvidar que aunque Marías se revela como autor y narrador de esta obra su voz sigue siendo igualmente ficticia: al presentar su relato como ficción o «como cuento» Marías insinúa que todo lo relatado no debe ser tomado como «verdadero». Recuérdese que no estamos hablando de un libro de memorias o de una autobiografía. La persona física de Javier Marías nunca debe ser confundida con la voz incorpórea que se presenta (o representa) como tal en el texto. El narrador de Negra espalda del tiempo, a pesar de llamarse Javier Marías, sigue siendo una criatura ficticia o de papel.

Con esta obra Javier Marías aspira a destruir el pacto de ficción por el que permanecen en suspenso las condiciones de «verdad» con las que nos manejamos en el mundo de lo real. El lector tiene en sus manos una «novela» que se presenta en cierto modo como reportaje periodístico. El narrador de Negra espalda del tiempo alude en alguna ocasión al carácter ficticio de este texto. Por ejemplo, al hablar del interés del profesor Francisco Rico en convertirse en personaje de ficción ${ }^{21}$, dice el narrador Marías: «Ahora he hablado de él aquí con su nombre, y con sus atributos. Pero esto no es una ficción, aunque sí debe de ser un cuento» ${ }^{22}$.

Es el lector el que debe decidir cómo va a entender el texto que tiene en las manos. Marías de nuevo se refugia en el aséptico terreno de la ambigüedad para situarse en el límite establecido convencionalmente entre realidad y ficción.

En el repaso a las novelas de Javier Marías se ha podido comprobar la sorprendente evolución que experimenta la voz narradora en sus ficciones. Mientras que en su primera novela Los dominios del lobo Marías intenta prescindir del narrador construyendo un pastiche manejado por un «narrador cámara» en sus novelas de madurez la voz del narrador en primera persona va a conducir un relato en el que la propia narración es la protagonista. El objetivo - a veces vital, al menos necesario- de los narradores de Javier Marías es relatar para entender lo que les rodea. Al hacer memoria -el relator cuenta en un presente que es el del discurso, como si tuviera a su receptor enfrente, dispuesto a escucharle sin prisas- de la

\footnotetext{
20 Javier MARÍAS, Vida del fantasma, op. cit., p. 14.

${ }_{21}$ Marías explica que el crítico es el trasunto real de dos personajes secundarios integrados en sus novelas anteriores: el profesor Del Diestro, personaje de Todas las almas, y el profesor Villalobos, de Corazón tan blanco.

22 Javier MARÍAS, Negra espalda del tiempo, op. cit., p. 74.
} 
historia que narra -obligatoriamente inserta en el pasado, aunque es un pasado que pesa enormemente en el presente- el narrador ordena, reflexiona, se explica a sí mismo e intenta explicarse ante los demás, como si temiera no ser comprendido. De este modo, mezclando presente y pasado (uno es producto de su pasado, y sólo a través de éste puede interpretarse en el presente, en lo que se es) se construye la novela a base de digresiones que entorpecen y a la vez organizan la narración.

Tras especializarse en el empleo de la primera persona narrativa Marías ha querido mostrar su propia voz. La voz del narrador aspira a confundirse así con la del autor en Negra espalda del tiempo, aunque no debe olvidarse que esta voz es igualmente ficticia. Javier Marías, que en sus inicios literarios evitó la forma autobiográfica de un modo tajante, se ha presentado como autor, narrador y protagonista de su último relato. Su indagación sobre los misterios del relato y sobre los poderes de la narración y de la palabra han llevado a este escritor a pasar al otro lado del espejo. Consciente de la dificultad de separar lo real de lo imaginado en su experiencia vital, Javier Marías ha presentado una obra que sobrepasa los límites entre los dos ámbitos y que debe entenderse también como un repaso a su trayectoria creativa. Sólo queda esperar que la anunciada segunda parte de Negra espalda del tiempo nos ayude a interpretar mejor este controvertido ensayo narrativo del autor. 


\section{RESUMEN}

La voz del narrador en la narrativa de Javier Marías, por Sandra Navarro Gil.

Una revisión rigurosa de la narrativa de Javier Marías debe partir del análisis de la figura del narrador, el componente más importante de la estructura narrativa.

La publicación de El hombre sentimental en 1986 va a marcar el inicio de una fructífera etapa creativa de Javier Marías basada en el empleo de una voz narradora en. primera persona.

Un narrador protagonista relata un retazo de su pasado que necesita ser contado para ser entendido. El resultado es una narración que nunca es lineal y que se enriquece con los continuos incisos digresivos del narrador. Javier Marías empleará el mismo tipo de voz narradora en sus siguientes ficciones, Todas las almas (1989), Corazón tan blanco (1992) y Mañana en la batalla piensa en mí (1994). En su último trabajo Negra espalda del tiempo (1998) un narrador llamado Javier Marías es el protagonista de una especie de novela situada a medio camino entre la realidad y la ficción. De nuevo una voz misteriosa es la única protagonista de una narración en espiral cuyo objetivo principal está centrado en su propio acto narrativo.

Palabras clave: Javier Marías, novelas, narrador, voz narradora, memoria, relato.

\section{SUMMARY}

A strict revision of Javier Marías's narrative must start from the analysis of the narrator's voice, the main narrative component in a novel.

El hombre sentimental's publication in 1986 is going to indicate the beginning of a fruitful creative stage of this writer based on the first person narrative voice use.

The protagonist narrator tells us a piece of his past that needs to be related in order to be understood. The result is a never linear narration that prospers thanks to the narrator's continuous digressive asides. Javier Marías went on with the same use of the narrator's voice in his following fictions Todas las almas (1989), Corazón tan blanco (1992) and Mañana en la batalla piensa en mí (1994). In his last work Negra espalda del tiempo (1998) a narrator called Javier Marías is the main character of a sort of novel placed between fiction and reality. Again a mysterious voice is the only protagonist of a spiral narration of which main purpose is its own narrative act.

Key words: Javier Marías, novels, narrator, narrative voice, memory, story. 